\title{
TEACHING AND LEARNING
}

what is the point? teaching graduate students how to construct political science research puzzles

\author{
karl gustafsson ${ }^{a, \star}$ and linus hagström ${ }^{b}$ \\ aSwedish Institute of International Affairs, P.O. Box 27035, 10251 Stockholm, Sweden \\ E-mail: karl.gustafsson@ui.se \\ 'Swedish Defence University, P.O. Box 27805, 11593 Stockholm, Sweden \\ E-mail: linus.hagstrom@fhs.se \\ ${ }^{*}$ Corresponding author.
}

https://doi.org/10.1057/s41304-017-0130-y; published online 31 July 2017

\begin{abstract}
One of the key challenges graduate students face is how to come up with a good rationale for their theses. Unfortunately, the methods literature in and beyond political science does not provide much advice on this important issue. While focusing on how to conduct research, this literature has largely neglected the question of why a study should be undertaken. The limited discussions that can be found suggest that new research is justified if it (1) fills a 'gap'; (2) addresses an important real-world problem; and/or (3) is methodologically rigorous. This article discusses the limitations of these rationales. Then, it proposes that research puzzles are more useful for clarifying the nature and importance of a contribution to existing research, and hence a better way of justifying new research. The article also explores and clarifies what research puzzles are, and begins to devise a method for constructing them out of the vague ideas and questions that often trigger a research process.
\end{abstract}

Keywords method; political science; problematization; research puzzles; research design

The online version of this article is available Open Access 


\section{INTRODUCTION}

A s political scientists, we spend much time writing: book manuscripts, conference papers and article drafts. Some texts are published in high-ranking peer-reviewed journals or by prestigious university presses, while others end up as working papers or even unpublished in desk drawers. Our peers clearly view some texts as meaningful, while others provoke their irritation or scorn.

As scholars, we not only write, but also read academic texts written by others: student theses, conference papers, manuscripts for peer review and published texts. Some of these works immediately capture our interest, and we keep reading almost effortlessly. Others can be 'boring, dogmatic, formalistic, and unsurprising' (Löwenheim, 2010: 1043). Why do we find some texts meaningful, while others come across as pointless, even though they may all appear to contain necessary components - aim, previous research, theory, method, data, analysis - and their authors have invested much time and effort in them?

The watershed is arguably whether a study has a clear rationale or justification. How to come up with one is a key challenge facing graduate students. Yet, the methods literature in and beyond political science provides them with scant advice on how to do so. While the social science methods literature is sizeable and covers many narrow issues, it has prioritized the question of how to conduct research, largely neglecting why a study should be undertaken. A rationale, it suggests, is provided by (1) filling a 'gap' in previous research; (2) addressing an important real-world problem; and/or (3) exercising methodological rigour.

While all three are necessary research components, we argue that they provide weak justifications for new research. Instead, we suggest that a well- constructed research puzzle is more useful as it clearly situates new research visà-vis the state of the art by explaining both how it contributes and why the contribution is necessary. Constructing research puzzles is not the only method for justifying new research, but we contend it is among the best ones. Neither the term research puzzle, nor the practice of formulating them, is new, however. Some works mention research puzzles but fail to explain their construction and function (Van Evera, 1997: 97-103; George and Bennett, 2004: 74-79; Flick, 2007: 22-23; Bloomberg and Volpe, 2008: 5-7; Della Porta and Keating, 2008: 266-267; Blaikie, 2010: 45-50; Flick, 2014: 12-13). This article contributes by fully explaining the advantage of research puzzles and by demonstrating how to construct them.

Our argument has educational value; it demonstrates how graduate students can conceive a clear rationale for their theses or dissertations. It also helps supervisors provide students with good advice. In fact, even established scholars can benefit from thinking more systematically about research puzzles, as it may help them communicate their contributions more clearly than is often the case in conference papers, manuscripts submitted for review and sometimes even in published work. Finally, we believe a more diffuse practice of formulating research puzzles could help facilitate debate and possibly even understanding across the boundaries that currently divide political science. Scholars might use different theories and methods for understanding or explaining politics, but we suggest they can construct similar research puzzles. Puzzles are a succinct way of delineating the nature of, and the need for, a specific contribution, regardless of whether qualitative or quantitative 
methods are used; whether 'why questions' or 'how possible questions' are asked; and, indeed, whether the research is 'problem', 'theory' or 'method' driven, in the language of Ian Shapiro (2002).

This article's aim is threefold: to explain why it is important to think hard about research puzzles; to clarify what a research puzzle is; and to start devising a method for constructing puzzles out of the vague ideas and questions that research processes often depart from. In the remainder, we first critically evaluate the three most widespread ideas on how to motivate research, that is, research gaps, real-world problems and methodological rigour. We then outline what a puzzle is, explain why puzzles are useful and indeed necessary, and present a strategy for constructing puzzles premised on problematization and abduction. Finally, we illustrate how our advice can be used to help students formulate research puzzles.

\section{HOW TO JUSTIFY NEW RESEARCH}

Critically assessing the three main suggestions identified above for justifying new research, this section also begins to delineate our alternative approach.

\section{GAPS}

In their immensely influential book on research design, Gary King, Robert O. Keohane and Sidney Verba argue that making a '[c]ontribution to an identifiable scholarly literature' is one of two important criteria for choosing a topic (1994: 15; see also Collier et al, 2004: 37-38). Such contributions, they suggest, can be made in various ways, one of which is to '[a]rgue that an important topic has been overlooked in the literature and then proceed to contribute a systematic study to the area' (King et al, 1994: 17). We agree about the need to
'... previous neglect does not automatically make the study of a topic necessary.'

clarify the contribution to existing research, and view close familiarity with the previous literature as crucial. However, we dispute the idea that a gap - understood as a topic that has not previously been analysed sufficiently motivates new research.

Other well-cited works on research design and methods also refer to gaps. Alexander L. George and Andrew Bennett write: 'The problem should be embedded in a well-informed assessment that identifies gaps in the current state of knowledge, acknowledges contradictory theories, and notes inadequacies in the evidence for existing theories' (2004: 74). While gaps are only part of what motivates new research for George and Bennett, they are nonetheless central. When addressing 'topic selection', Stephen Van Evera suggests: 'After each graduate school class, write an audit memo about the subject area of the course asking what was missing. What important questions went unasked?' (1997: 98, emphasis added). Furthermore, he advises that the introductory chapter of a dissertation should highlight 'the holes in the current literature' and the questions that 'have not been explored' (1997: 101, emphasis in the original).

Some may object that few established scholars consider gap-filling sufficient motivation for new research, but the idea remains influential. We often find that students justify their theses by arguing that a topic has been neglected and, indeed, that their supervisors and/or textbooks have taught them that such a rationale is both necessary and sufficient. However, previous neglect does not automatically make the study of a topic necessary. On the contrary, such inattention could indicate that it lacks implications for previous research. 
The main problem with the preoccupation with gaps is arguably that it focuses on mere inclusion/exclusion, rather than on why a certain gap is problematic and should be filled. Hence, gap filling underproblematizes the relationship to previous research. By failing to challenge assumptions in the existing literature, it risks reinforcing dominant theories (Alvesson and Sandberg, 2013). While we consider a gap to be insufficient reason for undertaking a study (Schmitter, 2008: 267; Alvesson and Sandberg, 2013: chapter 4), it is potentially a useful starting point, from which to proceed towards a research puzzle.

A similar argument suggests that new research can be motivated by studying what has yet to be sufficiently explored (Booth et al, 2008: chapters 3 and 4). Such a stance implies the possibility of achieving complete or sufficient knowledge. However, if we consider all scientific knowledge provisional, which is reasonable, no answer can constitute the last word' in a debate or on a certain topic. ${ }^{1}$ While existing research may be valuable, it will inevitably have missed important aspects or failed to illuminate them fully. To avoid falling into the gap trap once again, however, it is crucial to explain exactly why particular shortcomings need to be remedied and why certain understandings and explanations are worth pursuing beyond individual motivations.

\section{REAL-WORLD PROBLEMS}

The argument that new research is justified if it addresses pressing real-world problems is also influential in the methods literature. For example, King, Keohane and Verba's second criterion for how to choose a topic is that it is "important' in the real world' (1994: 15). Van Evera similarly emphasizes that political scientists should address questions 'relevant to real problems facing the real world' (1997: 97). ${ }^{2}$
Shapiro's suggestion that scholars should be problem driven rather than theory or methods driven, is similarly based on an understanding of 'problems' as 'the great questions of the day' (2002: 597). To Shapiro, examples include questions such as 'what the conditions are that make transitions to democracy more or less likely, or what influences the fertility rates of poor women' (Shapiro, 2002: 593; see also Flick, 2014: 12; Booth et al, 2008: chapter 4 ). In politics, numerous generic problems require attention. A case in point, central to the International Relations (IR) sub-discipline, is why states go to war. This is undoubtedly an important question, but formulated as such it is a political problem rather than a research puzzle.

Norman Blaikie defines a social problem as a state of affairs in society which policymakers, pundits and sociologists deem inadequate, and therefore in need of attention or a solution. A sociological problem, by contrast, is one that sociologists consider in need of a better explanation or enhanced understanding (Blaikie, 2010: 45). While scholars can pay attention to, and propose solutions for, social and political problems, we believe they need to frame their research differently from for example the media or the government. Hence, while political problems involve phenomena in need of political attention and resolution, research puzzles pinpoint issues in previous research in need of scholarly attention and resolution. This does not mean that research puzzles cannot have real-world significance, or that researchers should shun political problems. On the contrary, compelling research puzzles often have political significance (Mosser, 2010). A real-world problem might be the starting point for a research project, but is in itself insufficient as a justification for new research without an explanation of what makes the existing academic knowledge pertaining to it inadequate. 
Another reason why scholars should refrain from basing their research only on what is considered a political problem is that they risk being reduced to useful idiots. Doing such research does not automatically lead scholars to accept established definitions of problems, but it sets certain boundaries - the uncritical acceptance of which increases the risk of adopting status quo-oriented approaches. Of course, even when researchers control the formulation of problems and puzzles, the process is inevitably influenced by individual or collective norms and values (Rosenau, 1980: 31; Mosser, 2010: 1078). We argue below that such assumptions should be scrutinized and problematized as far as possible.

\section{METHODOLOGICAL RIGOUR}

Apart from gaps and real-world problems, the methods literature implies that rigorous research design and sophisticated methods themselves justify new research. However, as mentioned, the methods literature mainly focuses on how to do research, while discussions of why certain research is necessary are less common (e.g. Patton, 2001; Gerring, 2001; Marsh and Stoker, 2002; Klotz and Lynch, 2007; Silverman, 2011; Bryman, 2012). George and Bennett, for example, focus mostly on the purposes of case studies (2004: 75-79), and King, Keohane and Verba argue for the primacy of inference as a methodological principle, and do not clearly distinguish between 'topics', 'research questions' and 'puzzles' (1994: 14-19). Van Evera, similarly, is mostly preoccupied with arguing why case study method can be used in positivist theory-testing (1997: chapters 1 and 2 ). In comparison, his discussion of 'topic selection' seems more like an afterthought.
While rigorous methodology is necessary in all research, the works discussed above arguably espouse an excessively narrow understanding of what qualifies as such. More importantly for this article's purposes, we believe the existing methods literature can help determine how things are connected, but is of little use for arguing why knowledge about such connections is interesting or important in the first place. Hence, that empirical data and theory 'fit together' in the analysis is insufficient. Instead, a strong argument is necessary as to why new research can provide an explanation or understanding that differs from, and preferably supersedes, those found in existing scholarship.

One reason for this neglect is arguably the entrenchment in the social sciences of Karl Popper's (2002 [1934/1959]: 7-8) distinction between contexts of 'discovery' and 'justification'. Most agree with Popper that methods are essential in the context of justification - where hypotheses are tested and the inquiry is carried out. In contrast, the context of discovery - where the inquiry's aim is conceived - is often characterized as an irrational act involving intuition, coincidence and wild guesswork. Many methodologists therefore seem to believe that it is impossible to prescribe a method for developing new ideas. Against this deep-seated belief, we argue that it can be done by thinking methodically about research puzzles.

\section{RESEARCH PUZZLES: WHAT, WHY AND HOW?}

Both gaps and real-world problems can be used as starting points when developing research puzzles, and methodological rigour is important in all research projects, but none of these propositions sufficiently motivate new research. This section clarifies what a research puzzle is, why it is useful, and how one can be conceived. 


\section{WHAT A PUZZLE IS, AND HOW TO DEVELOP ONE}

In a 1980 book chapter, James Rosenau emphasized the importance of genuine puzzlement. He exemplified by asking: 'Why are most governments unable to control inflation?' (1980: 36). While we may agree that this is puzzling, without a clear connection to previous knowledge it resembles a political problem rather than a political science research puzzle. Rosenau's example takes the form of a 'why $x$ question', but even someone lacking the most rudimentary knowledge of state finances can formulate such a question (Zinnes 1980: 338). Developing the question into a research puzzle thus requires asking 'what is puzzling about how earlier research has described or explained this (allegedly puzzling) phenomenon?'

We propose that the following formula succinctly captures what research puzzles look like: 'Why $x$ despite $y$ ?', or 'How did $x$ become possible despite $y ?^{\prime 3}$ A puzzle thus formulated is admittedly a research question, but one requiring much closer familiarity with the state of the art than a 'why $x$-question'. The researcher considers the phenomenon $x$ puzzling since it happens despite $y$ - that is, previous knowledge that would seem contradicted by its occurrence. Hence, puzzlement arises when things do not fit together as anticipated, challenging existing knowledge.

It might be objected that some postpositivist approaches frame their research differently and indeed that a formula for devising puzzles serves knowledge-producing and hence political purposes the same way all methods do - by enacting the 'worlds' it analyses (Aradau and Huysmans, 2014). Put differently, it could be argued that our formula takes the $x$ and the $y$ as objectively existing and true. While this critique has a point, the $x$ and the $y$ do not need to be viewed as truths, but could be regarded as broadly shared beliefs or reasons for believing that something might be
'... puzzlement arises when things do not fit together as anticipated, challenging existing knowledge.'

'... Research puzzles can increase communicability within and between academic paradigms.'

true. Post-positivist approaches could address research puzzles constructed in line with our formula, and influential studies do so (e.g. Campbell, 1992; Doty, 1993; Weldes and Saco, 1996). Hence, we argue that puzzles are impartial to theoretical approach and that social science research, regardless of ontology and epistemology, benefits from constructing clear research puzzles, or from explicating tacit puzzles that sometimes exist between the lines. Research puzzles can increase communicability within and between academic paradigms and therefore enhance the likelihood that a study can become influential and have impact beyond the circle of theoretically or methodologically like-minded scholars.

As research puzzles pinpoint what is considered deviant or unexpected rather than normal, typical or expected, some may object that scholarship should describe and explain general patterns rather than exceptions. While we agree that social science should aim for generality, such an aim does not preclude addressing deviance. The discovery of unexpected deviation from a pattern established in earlier research can produce new knowledge that not simply confirms, but questions what we collectively believe we know. What has hitherto been considered a pattern is destabilized by conflicting observations or interpretations. Indeed, one might even argue that such puzzling 'anomalies' are important drivers 
of scientific progress, regardless of whether they lead to the correction or refinement of an existing theory or its abandonment in favour of an alternative theory (Kuhn, 1970; Lakatos, 1970; Vasquez, 1997; Elman and Elman, 2002). Discussions of anomalies in political science have primarily focused on their role in assessing the theoretical progress of research programs, rather than on puzzles as motivations for new research (e.g. Vasquez, 1997; Elman and Elman, 2002). While being informed by discussions in the former literature, this article is concerned with the latter issue.

The discussion above implies that a new explanation or theory can only be justified if it is seen as different from, and possibly opposed to, established knowledge. Without such differentiation, there is no way of determining whether it illuminates things better than previous research. The detection of unexpected difference - of tensions in the empirics or how they are interpreted - indicates the need for new research.

Exciting and innovative research often advances arguments that appear counterintuitive, which is why we agree with management scholars Mats Alvesson and Dan Kärreman that 'a desire to become challenged, surprised, bewildered, and confused' should 'take centre stage in research' (2007: 1269). We have the same desire when we read detective stories. The mere fact that a murder has taken place is usually insufficient; the impetus to continue reading is instead provided by complicating factors. Zinnes likens the relationship between the researcher and a puzzle to 'a detective confronted with a murder in a room with doors locked from the inside and no possible weapon within sight' (1980: 318). There is not just a corpse, but circumstances that make the murder seem truly puzzling. A detective story where the murderer is precisely the person who appeared guilty at the outset, by contrast, is not worth reading. Academic texts are no different; if they merely confirm what influential theories have long argued, they will make only limited contributions.

\section{PROBLEMATIZATION}

We believe researchers should continue to wrestle with theories, explanations, assumptions and variables that people have begun to treat as 'common sense'. Since new research is only new in relation to the old, this is also a useful way of deciding what to do new research on. Entering into critical dialogue with existing research can shed new light on theories and empirical phenomena alike. This is a strategy premised on 'problematization', that is, the practice of disrupting 'takenfor-granted 'truths" (Bacchi, 2012: 1).

Problematization can be used to turn a 'why $x$-question' into a research puzzle. For example, the social/political problem mentioned above, 'why do states go to war?', is clearly a 'why $x$-question'. It might be argued that the devastation and suffering brought about by wars at least makes the question implicitly puzzling. We are also eager to know why wars break out, hoping such enhanced understanding might help prevent future wars. However, since this argument depends on what is considered important in a particular society at a certain point in time, it is again a potentially status quooriented knowledge interest.

Creating a research puzzle, by contrast, necessitates making an inventory of previous research on the outbreak of wars, and problematizing parts of its assumptions or findings. To make the original question more puzzling, one should ask 'why not $x$ ?', that is, inquire into whether there is reason to believe that things are not connected as suggested by the original 'why $x$-question'. Hence, we could 
ask: 'Why not expect states to go to war?' The answer might be found in complex interdependence, regional integration, democratic peace or other theories that suggest that wars are less likely under certain circumstances (e.g. Keohane and Nye, 1977; Russett, 1993). We can then develop the original question: 'Why do some states go to war despite the existence of complex interdependence, regional integration, or democracy? (Examples would include the Kargil War between India and Pakistan in 1999 and the Russo-Georgian War in 2008.) The clear link to existing research makes the original question truly puzzling.

Some students not only motivate their theses with the dearth of research on a topic, but complain that there is no $y$ in the light of which $x$ is puzzling, that is, that there is no 'previous research'. A way of dealing with such a situation is to think more broadly, either theoretically or empirically. It may be possible, for example, to contextualize an issue by discussing what it is a case of, or how influential theories might tackle it. There may be no previous research on a certain war, but there are plenty of studies on other wars, and theories about the general phenomenon. Moreover, theories not usually applied to wars could also help provide new insights.

We can problematize not only approaches that we disagree with, but also ones that we are largely sympathetic to. Less thorough problematization involves demonstrating that parts of an explanation or theory are problematic, despite being valuable in other respects. More ambitious problematization may challenge the ontological or epistemological assumptions on which previous research is premised. A case in point is research raising the question of how to recognize a phenomenon when we see it. Such studies focus on key variables in an academic literature that are insufficiently substantiated or taken for granted, and can demonstrate that influential explanations rest on shaky ground. For instance, power transition is one explanation for why wars occur (Organski and Kugler, 1981), but due to conceptual complexities associated with the concept of power one could infer that power transitions are more difficult to spot than previous research admits (Chan, 2005). Despite such shakiness in the independent variable or explanans, scholars often continue to do research that takes the veracity of the explanation for granted. Similarly, a study can challenge influential ideas about what should be explained - the dependent variable or explanandum (Shapiro, 2002: 613-615). One could ask, for example, how we can recognize a war when we see one and how to differentiate it from 'skirmishes' or other clashes. Problematization is thus a way to construct puzzles premised on the question why previous research treats key variables as unproblematic, despite lingering problems related to conceptualization, measurement or interpretation.

Some assumptions are specific to one theory, while others are shared by several - even seemingly opposing - theories or entire paradigms. Research that challenges widespread conventions can completely overturn the basis for what might previously have seemed like a debate between conflicting positions (Alvesson and Sandberg, 2013). The more extensive or influential the problematized research, the greater its potential contribution.

Finally, we believe scholars must continue to problematize and reflect critically not only on previous research, but also on their own assumptions, concepts, theories, methods and conclusions. Since analysis, and the choices it is premised on always serves some interests, the distinction between political problems and political science puzzles may appear to get blurred. Indeed, by making knowledge claims, research inevitably projects power (Ackerly and True, 2008; Dauphinee, 2010). However, acknowledging the 
inevitably political nature of research is not equivalent to saying that political problems are sufficient motivation. It is rather a reminder that problematization must be premised on continued reflexivity (e.g. Amoureux and Steele, 2016).

\section{ABDUCTION}

Our experience is that graduate students and scholars take interest in phenomena and ask questions for very good reasons, but often fail to justify new research in a way that is sufficiently persuasive to others. Therefore, we believe it is useful to articulate an explicit research puzzle as early as possible in the research process (Rosenau, 1980: 34). Using problematization as a strategy helps justifying why an issue one has already decided to analyse deserves attention, but more fundamentally it helps improving the initial questions and alternative interpretations that one might bring to the table. Once established, the puzzle provides both a rationale and direction for the research process. The choices of aim, research questions, theory and, to some extent, methods and materials all tend to follow. In our experience, the careful construction of a research puzzle amounts to about half the job, especially when writing a thesis or journal article. Sufficient time should thus be allocated to it. Conversely, the absence of a research puzzle risks inviting inconsistencies into the research, some of which may be irreconcilable.

In conceptualizing the research puzzle as preferably preceding the investigation, we anticipate the objection that our advice is biased towards deduction. There is some truth in the allegation. Yet, it is highly unlikely that scholars undertake an investigation completely inductively, without being guided by any prior assumptions or preconceptions.

\section{'... Once established, the puzzle provides both a rationale and direction for the research process.'}

Since data are always theory dependent (Kuhn, 1970), any investigation is inevitably characterized by a degree of deduction. Having said that, most scholars arguably also engage in continuous inductive reflection, often even before realizing that a research process has begun. Since some ideas antedate each investigation, they should be articulated as early as possible. At the same time, it is important to be prepared for the possibility that one's initial research puzzle will require continual improvement and that a final version can only be constructed after completing the inquiry.

Charles Sanders Peirce called this continual movement to and fro between theory and empirics 'abduction' (1934). Although it has become associated with the context of justification, for Peirce and others abduction pertains more closely to the context of discovery, where hypotheses - and research puzzles are formulated (cf. Hanson, 1958: 72). Abductive reasoning often departs from puzzling cases, which need to be 'rendered intelligible' (Glynos and Howarth, 2007: 34; see also Beach and Pedersen, 2013: 19). The researcher seeks to conceptualize a plausible interpretation that can cast light on a specific case, but then moves on to inquire whether the interpretation can be extended to other cases. As the research process proceeds, the interpretation's scope, quality and distinctiveness develop in parallel. This shows how closely entwined the formulation of the research puzzle is with the actual investigation, and why the puzzle must be continually honed as the inquiry progresses. 


\section{FROM TOPIC TO RESEARCH PUZZLE: POWER SHIFT IN EAST ASIA}

This section puts our advice to use by demonstrating how to develop a vague idea into a research puzzle. Our example takes the form of a dialogue between person $A$, perhaps a graduate student, and person $B$, possibly a supervisor. The dialogue is fictitious although the example is closely related to our own empirical research interest - international politics in East Asia. After most of B's utterances, we formulate more general advice in brackets. This advice can hopefully serve as steps towards a recipe for formulating research puzzles, although the order of the steps is not fixed (see Table 1).

A: I want to do research on the East Asian power shift.

B: Since this is just a topic, I will ask questions to help you make necessary distinctions and construct a research puzzle. First, what power shift? [Make distinctions to narrow down your interest from a topic to an approximation of a research puzzle]

A: The current power shift from Japan to China.

B: Why do you find this ostensible power shift interesting? [Explicate the motives and preconceptions underlying your interest in an issue]

A: East Asia is increasingly significant in world politics. If a power shift occurs there it could have repercussions beyond the region.

B: This sounds like a political problem. Scholars also care about it, but must relate their interest to previous knowledge. What does the existing academic literature say about an East Asian power shift? [Approach your topic as a political science problem, rather than just a political problem]

A: Having read key texts I understand that previous research views Japan's power as diminishing relative to China's.

\section{Table 1: Advice on how to construct a research puzzle}

Towards a recipe for constructing research puzzles

1. Make distinctions to narrow down your interest from a topic to an approximation of a research puzzle

2. Explicate the motives and preconceptions underlying your interest in an issue

3. Approach your topic as a political science puzzle, rather than just a political problem

4. Since knowledge is necessary for constructing a research puzzle, read broadly in fields related to your problem area

5. Make sure your research aims to produce new knowledge

6. If the empirical record can be interpreted as conforming to existing assumptions, it is not clear why further research is necessary

7. A gap in previous research is a necessary, but insufficient, argument for new research

8. Problematize the often commonsensical assumptions on which previous knowledge is based

9. The bigger the target, the greater the potential contribution, so determine whether your observation is a case of a wider phenomenon

10. Clarify to what theory, explanation, or interpretation your own thesis would be counterintuitive

11. Construct a clear research puzzle using the puzzle formula 'why $x$ despite $y$ '

12. Pinpoint a research puzzle early in the research process, but be prepared to find other potentially more significant problems - possibly at higher levels of abstraction - as your knowledge expands 
B: How can you contribute to this research? [Make sure your research aims to produce new knowledge]

A: Existing research primarily analyses issues related to economic and military capabilities, and regional territorial conflicts. There is a gap concerning who has agenda-setting power in regional organizations.

B: Since the existence of a gap has little intrinsic value, you must clarify why it is necessary to fill it: How could research on agenda-setting power in regional organizations help illuminate East Asian power relations? [A gap in previous research is a necessary, but insufficient, argument for new research]

A: We can assume that Japan has been influential in regional organizations for decades and has exercised power over the agendas of these organizations. If power is indeed shifting from Japan to China, it should be detectable in this area.

$\mathrm{B}$ : You are making many assumptions, each of which deserves its own investigation. For example, what exactly is agenda-setting power and how can we recognize its exercise when we see it? Moreover, do we know Japan previously exercised such power? And are regional organizations important in East Asia? [Problematize the often commonsensical assumptions on which that previous knowledge is based]

A: How do I address those questions?

$\mathrm{B}$ : Absorb yourself even more in the relevant literature. [Since knowledge is necessary for constructing a research puzzle, read broadly in fields related to your problem area]

A: After reading more, I understand that agenda-setting power is the capacity to decide which questions are included on or excluded from the political agenda. I also realize that while East Asian regional organizations are deemed less important than, for example, European ones, they are nonetheless active in important issue areas. There is no research that explores whether Japan has exercised such agenda-setting power in the past.

B: Okay, do decisions by organizations such as ASEAN + 3 (Association of Southeast Asian Nations plus China, Japan and South Korea) somehow contradict your assumptions about regional agenda-setting power? [If the empirical record can be interpreted as conforming to existing assumptions, it is not clear why further research is necessary]

A: Yes, I have identified a common assumption in the literature that Japan had agenda-setting power commensurate with its economic capabilities, but empirical analysis demonstrating this is lacking.

B: This gets you close to a research puzzle, but a different one than you envisaged: Why has Japan been attributed so much agenda-setting power despite limited empirical evidence? [As your understanding deepens, be prepared to tweak your research puzzle accordingly]

A: Okay, can I do my research now?

B: Not yet. First you need to consider whether this discrepancy applies only to Japan or is a broader phenomenon. For example, if Japan was attributed agendasetting power before the ostensible power shift, is it possible that China is currently ascribed such power on similarly shaky grounds? This would suggest the existence of a meta-level agendasetting power that previous analyses have missed. [The bigger the target, the greater the potential contribution, so determine whether your observation is a case of a wider phenomenon]

A: Can the discrepancy between assumptions about Japan and the empirics also motivate a more thorough empirical analysis of agenda-setting power in East Asia?

B: Absolutely, and the analysis does not have to be limited to East Asia. The target could be an influential theory, according to which agenda-setting power follows from economic capabilities: the hypotheses derived from such a theory 
would seemingly be falsified by available empirics. In other words, theory $C$ states that agenda-setting power follows from economic capabilities. The available empirics, however, do not support the assumption that Japan has had agendasetting power commensurate with its economic strength. Why, has Japan not had considerable agenda-setting power, despite its possession of huge economic capabilities for so long? How can this anomaly for theory $C$ be explained? [Clarify to what theory, explanation, or interpretation your own thesis would be counterintuitive]

A: Yes, that certainly is an interesting research question.

B: It is not simply a question. Since it contains both an observation and a theoretical understanding to which the observation is paradoxical, it is a research puzzle. [Construct a clear research puzzle using the formula 'why $x$ despite $y^{\prime}$ ]

A: Okay, great, thanks.

B: I know you are eager to get started with your thesis, but constructing research puzzles is like peeling an onion: each layer hides another layer. For example, I suggested that the notion of meta-level agenda-setting power might help us understand the puzzle we just constructed. If you aim to contribute mainly to the study of East Asian international relations, you might be able to draw on theoretical work on meta-power or discursive power to craft an explanation. But you could also ask: does anything about my puzzle remain puzzling to this literature? If so, you could make a theoretical contribution extending beyond what you originally intended. [Pinpoint a research puzzle early in the research process but be prepared to find other potentially more significant puzzles that lead to greater contributions possibly at higher levels of abstraction as your knowledge expands]

\section{CONCLUSION}

One of the greatest challenges for graduate students is how to come up with a clear rationale for their dissertations and theses. This article has argued that research puzzles are more useful for that endeavour than the most common propositions in the existing methods literature: that new research should fill gaps, address important real-world problems and/or be methodologically rigorous. In contrast, a research puzzle often provides a sufficient justification. Research puzzles are different from societal or political problems, primarily because they are explicitly contextualized in relation to previous knowledge and research. Good research puzzles have in common that they problematize something in existing research. A wellformulated research puzzle provides direction and coherence to the research process and governs all other key choices, such as the aim, research questions, material and method. Our argument should not be misinterpreted as suggesting that research puzzles are the only way for providing new research with a rationale. Future research should identify and develop ways for constructing other types of justifications.

\section{Acknowledgements}

The authors would like to express their gratitude to participants in seminars at Freie Universität Berlin, Lund University and Warwick University, as well as to Stefan Borg, Niklas Bremberg, Johan Engvall, Johan Eriksson, Ulv Hanssen, Björn Jerdén, Regina Karp, Wrenn Yennie Lindgren, Tom Lundborg, Nicola Nymalm, Gunilla Reischl, Anke Schmidt-Felzmann, Oliver Turner, Mikael Weissmann and Stephanie Winkler for their useful comments on earlier versions of this article. 


\section{Notes}

1 The present article is no exception; criticism of it is likely to enhance our collective understanding of research puzzles.

2 Neither King, Keohane and Verba nor Van Evera argues that a real-world problem is sufficient motivation for new research. Instead, the former consider it a necessary criterion along with the need to make a specific contribution to an identifiable scholarly literature (1994: 15-17), and the latter puts it alongside gaps and 'key disputes of fact or theory' (1997: 99). Nonetheless, both works strongly emphasize the importance of real-world problems.

3 Because of space restrictions, the remainder of this article discusses 'why $x$-questions', but the discussion is applicable to 'how possible questions' too.

\section{References}

Ackerly, B. and True, J. (2008) 'Reflexivity in practice: Power and ethics in feminist research on international relations', International Studies Review 10(4): 693-707.

Alvesson, M. and Kärreman, D. (2007) 'Constructing mystery: Empirical matters in theory development', Academy of Management Review 32(4): 1265-1281.

Alvesson, M. and Sandberg, J. (2013) Constructing Research Questions: Doing Interesting Research, London: Sage.

Amoureux, J.L. and Steele, B.J. (eds.) (2016) Reflexivity and International Relations: Positionality, Critique, and Practice, London: Routledge.

Aradau, C. and Huysmans, J. (2014) 'Critical methods in international relations: The politics of techniques, devices and acts', European Journal of International Relations 20(3): 596-619.

Bacchi, C. (2012) 'Why study problematizations? Making politics visible', Open Journal of Political Science 2(1): 1-8.

Beach, D. and Pedersen, R.B. (2013) Process-Tracing Methods: Foundations and Guidelines, Ann Arbor: University of Michigan Press.

Blaikie, N. (2010) Designing Social Research, 2nd edn, Cambridge: Polity Press.

Bloomberg, L.D. and Volpe, M. (2008) Completing Your Dissertation: A Roadmap from Beginning to End, London: Sage.

Booth, W.C, Colomb, G.G. and Williams, J.M. (2008) The Craft of Research, Chicago: The University of Chicago Press.

Bryman, A. (2012) Social Research Methods, 4th edn, Oxford: Oxford University Press.

Campbell, D. (1992) Writing Security: United States Foreign Policy and the Politics of Identity, Manchester: Manchester University Press.

Chan, S. (2005) 'Is there a power transition between the US and China? The different faces of national power', Asian Survey 45(5): 687-701.

Collier, D., Seawright, J. and Munck, G.L. (2004) 'The Quest for Standards: King, Keohane and Verba's Designing Social Enquiries', in H.E. Brady and D. Collier (eds.) Rethinking Social Inquiry: Diverse Tools, Shared Standards, Lanham, MD: Rowman and Littlefield, pp. 21-50.

Dauphinee, E. (2010) 'The ethics of autoethnography', Review of International Studies 36(3): 799-818.

Della Porta, D. and Keating, M. (eds.) (2008) Approaches and Methodologies in the Social Sciences: A Pluralist Perspective, Cambridge: Cambridge University Press.

Doty, R.L. (1993) 'Foreign policy as social construction: A post-positivist analysis of US counterinsurgency policy in the Philippines', International Studies Quarterly 37(3): 297-320.

Elman, C. and Elman, M.F. (2002) 'How not to be Lakatos intolerant: Appraising progress in IR research', International Studies Quarterly 46(2): 231-262.

Flick, U. (2007) Designing Qualitative Research, London: Sage.

Flick, U. (2014) An Introduction to Qualitative Research, 5th edn, London: Sage.

George, A.L. and Bennett, A. (2004) Case Studies and Theory Development in the Social Sciences, Cambridge: MIT Press.

Gerring, J. (2001) Social Science Methodology: A Critical Framework, Cambridge: Cambridge University Press.

Glynos, J. and Howarth, D. (2007) Logics of Critical Explanation in Social and Political Theory, London: Routledge. 
Hanson, N.R. (1958) Patterns of Discovery: An Inquiry into the Conceptual Foundations of Science, Cambridge: Cambridge University Press.

Keohane, R.O. and Nye, J.S. Jr (1977) Power and Interdependence: World Politics in Transition, Boston: Little, Brown.

King, G., Keohane. R.O. and Verba, S. (1994) Designing Social Inquiry: Scientific Inference in Qualitative Research, Princeton: Princeton University Press.

Klotz, A. and Lynch, C. (2007) Strategies for Research in Constructivist International Relations, Armonk, NY: ME Sharpe.

Kuhn, T.S. (1970) The Structure of Scientific Revolutions, 2nd ed. Chicago: University of Chicago Press.

Lakatos, I. (1970) 'Falsification and the Methodology of Scientific Research Programmes' in I. Lakatos and A. Musgrave (eds.) Criticism and the Growth of Knowledge, Cambridge: Cambridge University Press, pp. 91-196

Löwenheim, O. (2010) 'The 'I' in IR: An autoethnographic account', Review of International Studies 36(4): 1023-1045.

Marsh, D. and Stoker, G. (2002) Theory and Method in Political Science, 2nd ed. New York: Palgrave Macmillan.

Mosser, M.W. (2010) 'Puzzles versus problems: The alleged disconnect between academics and military practitioners', Perspectives on Politics 8(4): 1077-1086.

Organski, A.F.K. and Kugler, J. (1981) The War Ledger, Chicago: University of Chicago Press.

Patton, M.Q. (2001) Qualitative Evaluation and Research Methods, 3rd ed. London: Sage.

Peirce, C.S. (1934) Collected Papers of Charles Sanders Peirce, vols. 5-6, Cambridge, MA: Harvard University Press.

Popper, K. (2002 [1934/1959]) The Logic of Scientific Discovery, New York: Routledge. First published in German in 1934; first English translation in 1959.

Rosenau, J.N. (1980) 'Thinking theory thoroughly', in J.N. Rosenau (ed.) The Scientific Study of Foreign Policy, London: Frances Pinter, pp. 29-37.

Russett, B. (1993) Grasping the Democratic Peace, Princeton, NJ: Princeton University Press.

Schmitter, P. (2008) 'The design of social and political research', in D. Della Porta and M. Keating (eds.) Approaches and Methodologies in the Social Sciences: A Pluralist Perspective, Cambridge: Cambridge University Press, pp. 263-295.

Shapiro, I. (2002) 'Problems, methods, and theories in the study of politics, or what's wrong with political science and what to do about it', Political Theory 30(4): 596-619.

Silverman, D. (ed.) (2011) Qualitative Research, 3rd ed. London: Sage.

Van Evera, S. (1997) Guide to Methods for Students of Political Science, Ithaca: Cornell University Press.

Vasquez, J.A. (1997) 'The realist paradigm and degenerative versus progressive research programs: An appraisal of neotraditional research on Waltz's balancing proposition', American Political Science Review 91(4): 899-912.

Weldes, J. and D. Saco (1996) 'Making state action possible: The United States and the discursive construction of 'The Cuban Problem', 1960-1994', Millennium: Journal of International Studies 25(2): 361-395.

Zinnes, D.A. (1980) 'Three puzzles in search of a researcher', International Studies Quarterly 24(3): $315-342$.

\section{About the Authors}

Karl Gustafsson is Associate Professor of Political Science and Senior Research Fellow at the Swedish Institute of International Affairs. He has published or has forthcoming peerreviewed articles in Memory Studies, Review of International Studies, Cooperation and Conflict, China: An International Journal, Global Affairs, The Pacific Review and Asian Perspective. His article 'Memory politics and ontological security in Sino-Japanese relations' won the Wang Gungwu prize for best article published in Asian Studies Review in 2014.

Linus Hagström is Professor of Political Science at the Swedish Defence University and Senior Research Fellow at the Swedish Institute of International Affairs. He has recently published articles in The Washington Quarterly, Review of International Studies, European Journal of International Relations, Chinese Journal of International Politics and Global Affairs and edited special issues for Asian Perspective and The Pacific Review. 

licenses/by/4.0/), which permits unrestricted use, distribution, and reproduction in any medium, provided you give appropriate credit to the original author(s) and the source, provide a link to the Creative Commons license, and indicate if changes were made. 